\title{
Improving Clinical Teaching of Fourth Year Anaesthesia Students: The Case of Wolaita Sodo University
}

\author{
Mohammed Suleiman Obsa ${ }^{1}$, , Getahun Molla Shanka ${ }^{2}$, Getahun Dendir Wolde ${ }^{1}$, \\ Wolde Facha Faltamo ${ }^{3}$ \\ ${ }^{1}$ School of Anesthesia, Wolaita Soddo University, Wolaita Soddo, Ethiopia \\ ${ }^{2}$ School of Medicine, Wolaita Soddo University, Wolaita Soddo, Ethiopia \\ ${ }^{3}$ School of Public Health, Wolaita Soddo University, Wolaita Soddo, Ethiopia
}

\section{Email address:}

msuleiman43@gmail.com (M. S. Obsa), shankamolla@yahoo.com (G. M. Shanka), gechgetahun@gmail.com (G. D. Wolde),

woldiefacha@gmail.com (W. F. Faltamo)

${ }^{*}$ Corresponding author

\section{To cite this article:}

Mohammed Suleiman Obsa, Getahun Molla Shanka, Getahun Dendir Wolde, Wolde Facha Faltamo. Improving Clinical Teaching of Fourth Year Anaesthesia Students: The Case of Wolaita Sodo University. International Journal of Biomedical Engineering and Clinical Science. Vol. 6, No. 3, 2020, pp. 55-59. doi: 10.11648/j.ijbecs.20200603.11

Received: August 18, 2020; Accepted: September 21, 2020; Published: September 25, 2020

\begin{abstract}
Background: Anesthesia programs prepare students through course work that develops knowledge and skills in anesthesia practice as well as in organizational and leadership skills, and courses are strongly related to theoretical and clinical teaching. In health science professions, clinical or practical experience is necessary to develop knowledge and skills acquired theoretically. For this reason, both theoretical and clinical components of education are included in health science educational programmes. The purpose of the theoretical component is to provide students the opportunity to learn principles and concepts relevant for professional performance. Objective: To improve the practical teaching of fourth-year anesthesia students, CHSM, WSU from March 10-April 10, 2019. Methods and Materials: A cross-sectional study design was employed. Training was given for data collectors and supervisors. Regular supervision and follow-up were performed. Questionnaires was used as data collection tools. Conclusion: Anesthesia students' clinical experiences are an important element of the profession as well as clinical teaching, which is the cornerstone of education.
\end{abstract}

Keywords: Anesthesia, Clinical Teaching, Improving

\section{Introduction}

\subsection{Background}

Anesthetists are vital in hospital operating rooms, surgery centers, physicians' offices and beyond. Working alongside anesthesiologists, surgeons and others, anesthetists administer anesthesia for all types of surgical cases, from the simplest to the most complex. Anesthesia practice covers the continuum of care from preoperative assessment to discharge from the recovery unit. Anesthetists interview and assess each patient to best formulate and implement an individualized plan of care while collaborating with members of a multidisciplinary health care team.

The anaesthesia programme prepares students through course work that develops knowledge and skill in anaesthesia practice as well as in organizational and leadership skills, and the courses are strongly related to theoretical and clinical teaching. In this regard, anaesthesia students' clinical experiences are an important element of the anaesthesia profession as well as clinical teaching in which students learn how to apply anaesthesia knowledge, skills, patient communication and professionalization and prepare themselves for practice in future workplaces [1].

Several studies have shown that the learning environment is a significant component with respect to clinical learning and learning outcomes [2]. Throughout anesthesia history, clinical placements play an essential role in the learning process of anesthesia students [3]. Additionally, anesthesia students may think that the clinical environment is the most influential educational component to acquire anesthesia knowledge and skills [3]. The clinical environment consists 
of inpatient, hospital outpatient and community settings, which have specific challenges [4].

Anesthesia students look for a favorable learning environment, and their perception of the clinical learning environment is different from their perception of the actual learning environment [4]. The most important step in developing continuing anesthesia education is to study anesthesia students' perceptions and to find the impacts of educational programs on bachelor's degrees. As a part of their clinical education, anesthesia students participate in new clinical environments to gain clinical experience. Learning in these settings depends on encouraging the environment based on psychological and pedagogical aspects. This is achieved by the teacher-student connection and considerable learning situations that form a pedagogic atmosphere [4, 5]. Health care professionals are expected to practice evidence-based practices. Consequently, by the time students in health care professions graduate, they need to be confident in practicing evidence-based education. This is in agreement with the Sicily statement on evidence-based practice (EBP), which recommends that the necessary knowledge, skills and attitudes of EBP be incorporated into the curricula [6]. Finding research evidence has also been identified as a problem in surveys among undergraduate medical students, as students' searching was inefficient, and they reported performing searches in single journals rather than clinical databases when they had clinical questions [7].

\subsection{Statement of Problem}

In health science professions, clinical or practical experience is necessary to develop knowledge and skills acquired theoretically. For this reason, both theoretical and clinical components of education are included in health science educational programmes [8]. The purpose of the theoretical component is to provide students the opportunity to learn principles and concepts relevant for professional performance [9]. The clinical practice, on the other hand, is expected to allow students to understand the theoretical reasoning that underlies the purpose of clinical tasks while allowing students the experience of performing that task. Clinical practice experience is the 'heart' of professional education, as it provides students with the opportunity to consolidate knowledge, socialize into the professional role and acquire professional values [10].

Educational history suggests that both theory and practice in the past have been delivered to students by educators mostly at lecture halls and the institution's clinical laboratories or facilities. However, lack of experience in clinical settings was often observed in health education programmes [11]. This necessitated the incorporation of clinical rotation in health care programmes to provide students opportunities for direct contact with patients and their relatives, hospital staff and hospital equipment. The clinical rotation component of education is meant to provide students the opportunity to integrate skills and knowledge from the classroom setting into the clinical practice setting [12]. It also offers students the ability to learn about the complex health issues of patients, practice selected technical skills and develop communication skills in the clinical setting. In addition, clinical rotations help students engage in the clinical environment acquire new knowledge and skills and participate alongside many health professionals and thereby learn how to work in a team [12].

Effective clinical rotations are essential for improving competence and research - based education in anesthesia [13]. However, diverse challenges, including the theorypractice gap encountered by students during clinical rotations, have been reported. The theory-practice gap is the discrepancy between what is taught (theory) in the classroom and what is actually practised clinically. Identified causes of the theory=practice gap during clinical rotations include the supervisors' and preceptors' level of experience and competence. In addition to discrepancies between theory and organizational protocols, heavy workloads and poor supervisee-supervisor relationships have all been cited as causes of the theory-practice gap [14]. Other studies have also found the theory-practice gap to be associated with lecturers' changing role from 'hands on' supervision of students to focus on more research. The consequence is that some practicing professionals assume supervisory roles with insufficient preparation and are often unaware of the associated educational goals required of the clinical supervisory roles [15]. Lack of communication and agreement between the educational institution and the clinical supervisors involved in students' learning is said to have a serious problem in theory-practice gaps elsewhere. Therefore, investigating areas of theory-practice gap and providing measures to curb it cannot be overemphasized [15, $16]$.

The complaints of some clinical students about the dichotomy or existence of the theory-practice gap have, however, not been substantiated. This study therefore investigated the issue of the theory-practice gap of third-year anesthesia students to perform the most frequently performed procedure in Wolaita Soddo University Teaching and Referral Hospital.

\subsection{Significance of Study}

The primary responsibility for nurse anesthesia clinical education lies with working in the clinical setting. Despite the importance of clinical education within the framework of anesthesia educational programs, little has been done to support and educate. A different skill set is required when teaching others to deliver anesthesia care. There is increased responsibility for determining the appropriate balance between allowing student independence and fostering educational objectives and continuing to ensure safe, quality care for the patient. One of the most important purposes in clinical education is decreasing the gap between the actual and expected clinical environments that leads to an increased clinical learning performance. Therefore, it is of interest to examine how anesthesia students perceive clinical learning environments that they are assigned to as parts of anesthesia education. Hence, maintaining perceptions of actual and 
expected clinical environments is very important to deliver safe and culturally competent anesthesia care to patients of all ages and physical conditions, to develop and implement anesthesia management throughout the per anesthetic continuum using a variety of current anesthesia techniques, agents and equipment, to apply knowledge to practice in decision-making and problem-solving and to provide nurse anesthesia care based on sound principles and research evidence. Therefore, this action research aimed to improve the practical teaching of fourth-year anesthesia students, CHSM, WSU, from March 10-April 10, 2019.

\section{Methods and Materials}

\subsection{Study Area and Period}

The study was conducted at Wolaita Sodo University Teaching and Referral Hospital from March 10 to 15/2019. The hospital is found in Sodo town, which is located $326 \mathrm{~km}$ away from Addis-Ababa to the south along the main highway that leads to Arbaminch via Hosanna. The total population of the Wolaita zone is 1.7 million, of which 120,000 is the population of Sodo Town. There are three hospitals and seventy health centers in the Wolaita zone. The university has three campuses, of which the Otona campus has been training health cadres. Currently, the campus has been running ten regular undergraduate and seven postgraduate programs.

Study design: A cross-sectional study design was used to conduct our study.

\subsection{Population}

All fourth-year anesthesia students were the source population, and selected fourth-year anesthesia students who were available during data collection were the study population.

\subsection{Sample Size Determination and Sampling Technique}

Census was used to include all study participants.

Data collection instruments, procedure and Data Quality Control.

Questionnaires were used as data collection instruments. Two days of training was given to the data collectors and supervisors. Supervisors were cross checked for completeness and accuracy of data on a daily basis. We formed one group of students from fourth-year anaesthesia students who completed anaesthesia practice three and the research proposal. The students were asked to complete questionnaires.

The initial questions posed were as follows:

How would you typically see anesthesia courses (both theory and practice)?

Have you implemented what you have learned in theory during clinical attachments (lecture or tutorial)?

How would you see skill lab of anesthesia departments in improving clinical practices?

How would you explain to others your approach of implementing what you have learned in theory into practice?

\section{Result}

The main themes that we identified are presented in this section, illustrated by participation in the skill lab and clinical practical site.

Mr. X have risen that they need to repeatedly practice in skill labs to confidently improve practice in clinical settings. He also noted he needs to attend practical courses by DOPS (Direct Observation Procedural Skill) CBD (Case Based Discussion).

The themes identified by different members of our research team, including themes illustrated in the video clips, were discussed and combined into a single list. Together, they illustrated that frequent exposure to simulation in the skill lab is more important than attending most theory in class, as this helped them gain confidence and improve their exposure.

Those participants seemed happy to utilize several of them in their learning.

We thought support from peers definitely complemented each other because there were a real difference in being told something and being taught something and two people not truly knowing but then finding out the answer together.

They need to attend demonstration and re demonstration in skill lab.

They did not actually have DOPS (direct observation procedural skill), but they rarely practiced CBD (clinicalbased discussion) less frequently.

We didn't actually have a study group, but when we had the practical, like the one we just had, us and two other friends would just go direct together.

Clinical practice in the skill lab and clinical setting strengthened the skill of learners. This should be supplemented by case-based discussion and direct observation.

After the assessment, we provided a demonstration in the skill lab to the students for one week and assessed its impacts on student performance; during the assessment, we identified that repeated exposure to the skill lab can build confidence in learners and their performance.

In addition, we identified that we can improve students' clinical practice/teaching by teaching students on case-based discussion and direct observation of procedural skills. This helps them to convert what they have learned into practices.

We study with another two that we've met through the course and so we got together on weekends and go over stuff and look at the quizzes and the answers and everything and just try to..., but it's worked really, really well for me, because they always know..., we know something that they don't and they know something that I don't. It's really great. It's really been helpful.

Both in theory and practical learning, it was very important to have a variety of teaching methods. In theory, the regular quizzes and assignments provided plenty of material for group discussion and learning, and indeed, students felt that their study group provided a good format for tackling the assessment. Yeah, and we focused on the, yeah, the quizzes a 
lot, because the answers from that are sort of, we think are pretty fundamental. So, if we can understand that well, that's going to help us in the exam and further down the track.

There were interesting descriptions of how students identified potential group members and how they set up their study groups. Their approaches included attending the first few tutorials and actively looking for likely people, in some cases people who shared their characteristics (such as being mature-aged students). Others reported eavesdropping on other members of the class to check whether they would be compatible members.

In practice, simulation in a skill lab and direct performance in a health care facility are performed. We have demonstrated the session in a skill lab for one week and observed its impacts on them. With our study group, we have identified that repeated practice in a skill lab and clinical setting can build learners and their performance. In addition, we have identified that direct observation and case-based discussion were very important to convert what they have gained in theory into practice. In addition, a variety of teaching methods and assessment methods during the course helped them to obtain more knowledge.

\section{Discussion}

Health care undergraduate students expected to practice evidence-based after they graduated. Clinical instructors were in a position to influence students during clinical education and thus important potential role models in evidence-based practice. Actions from academic and clinical settings were needed to improve competence in evidencebased practice among clinical instructors.

Anesthesia education was strongly related to theoretical and clinical teaching. In this regard, anesthesia students' clinical experiences were an important element of the nursing profession as well as clinical teaching, which was the cornerstone of nursing education. In this learning environment, students learn how to apply knowledge, nursing skills, patient communication and professionalization and prepare themselves for practice in future workplaces.

Additionally, anesthesia students may think that the clinical environment was the most influential educational component to acquire nursing knowledge and skills. The clinical environment consists of inpatient, hospital outpatient and community settings, which have specific challenges. Pringle and Green believed that nursing clinical experience was a factor that affected nursing student attribution.

The message from the skill lab demonstration was that many students can build their confidence and skill. However, these should be supplemented by DOPS, CBD and other clinical teaching methodologies to improve both theory and practical teaching.

In theory, learning formal lectures and tutorials play a smaller part in their overall learning; the lectures can be overwhelming in terms of material, and the tutorials were less useful, sometimes because they include other students who have not made a similar commitment to their learning.
However, the student leaders and participants in this research were volunteers. They were likely to represent those who were most organized and committed, and indeed they talked at times about some other students who were not working at this level.

The students in this anesthesia course reported a different experience with the main focus on trying to understand clinical practice through skill lab demonstration, direct observation procedural skill and others. However, they did talk about the problems of making the transition from theory to practice.

They were aware of the contrast between their selforganized study groups and the learning organized by their lecturers and tutors and practical groups. They saw a benefit in both aspects. Though they realized that their study groups were their own responsibility, they suggested various ways in which their practical lecturers and tutors could assist the process of forming and keeping study groups.

\section{Conclusion}

As clinical instructors were in a position to influence students during clinical education, instructors should use a variety of both clinical and theoretical in skill labs and clinical settings. Therefore, actions from academic and clinical settings are needed to improve competence in evidence-based practice among clinical students.

\section{Competing Interest}

The authors declare that they have no competing interests.

\section{Author Contributions}

MS and GD contributed to the conception, design of the study, data acquisition, data entry, analysis and interpretation of the data and drafted and revised the manuscript. GM and WF contributed to the conception and assisted in the initial design of the study, analyzed and interpreted the data and critically revised the manuscript. All authors read and approved the final manuscript.

\section{Funding}

Wolaita Sodo University, but the funder has a role in publishing this research.

\section{Availability of Data and Materials}

Data will be available with reasonable request from the corresponding author.

\section{Acknowledgements}

We would like to express our deep gratitude to Wolaita Sodo University, Higher diploma program (HDP) office for providing us this opportunity. 


\section{References}

[1] Ramani S, Leinster S: AMEE Guide no. 34: Teaching in the clinical environment. Medical teacher 2008, 30 (4): 347-364.

[2] Andrews GJ, Brodie DA, Andrews JP, Hillan E, Thomas BG, Wong J, Rixon L: Professional roles and communications in clinical placements: A qualitative study of nursing students' perceptions and some models for practice. International Journal of Nursing Studies 2006, 43 (7): 861-874.

[3] Berntsen K, Bjørk IT: Nursing students' perceptions of the clinical learning environment in nursing homes. Journal of Nursing Education 2010, 49 (1): 17-22.

[4] Pringle D, Green L: Examining the causes of attrition from schools of nursing in Canada. Office of Nursing Policy, Health Canada Retrieved June 2004, 16: 2008.

[5] Zuzelo PR: Describing the RN-BSN learner perspective: Concerns, priorities, and practice influences. Journal of professional nursing 2001, 17 (1): 55-65.

[6] Dawes M, Summerskill W, Glasziou P, Cartabellotta A, Martin J, Hopayian K, Porzsolt F, Burls A, Osborne J: Sicily statement on evidence-based practice. BMC medical education 2005, 5 (1): 1.

[7] Coomarasamy A, Khan KS: What is the evidence that postgraduate teaching in evidence based medicine changes anything? A systematic review. Bmj 2004, 329 (7473): 1017.

[8] Botwe BO, Arthur L, Tenkorang MK, Anim-Sampong S:
Dichotomy between theory and practice in chest radiography and its impact on students. Journal of medical radiation sciences 2017, 64 (2): 146-151.

[9] Msiska G, Smith P, Fawcett T: The "lifeworld" of Malawian undergraduate student nurses: The challenge of learning in resource poor clinical settings. International Journal of Africa Nursing Sciences 2014, 1: 35-42.

[10] Phillips DE: Integrating academic and clinical learning using a clinical swallowing assessment. Communication Disorders Quarterly 2013, 34 (4): 256-260.

[11] Gillespie M, McFetridge B: Nurse education-the role of the nurse teacher. Journal of clinical nursing 2006, 15 (5): 639644.

[12] Swinny B, Brady M: The benefits and challenges of providing nursing student clinical rotations in the intensive care unit. Critical Care Nursing Quarterly 2010, 33 (1): 60-66.

[13] Baird M: Towards the development of a reflective radiographer: challenges and constraints. Biomedical imaging and intervention journal 2008, 4 (1).

[14] Baxter P: The CCARE model of clinical supervision: Bridging the theory-practice gap. Nurse education in practice 2007, 7 (2): 103-111.

[15] Barrett D: The clinical role of nurse lecturers: past, present, and future. Nurse Education Today 2007, 27 (5): 367-374.

[16] Lambert V, Glacken M: Clinical education facilitators: a literature review. Journal of clinical nursing 2005, 14 (6): 664-673. 